\title{
Directly UV written silica-on-silicon planar waveguides with low insertion loss
}

\section{Zauner, Dan; Svalgaard, Mikael; Kristensen, Martin}

\section{Published in:}

Technical Digest Optical Fiber Communication Conference and Exhibit

Link to article, DOI:

10.1109/OFC.1998.657285

Publication date:

1998

Document Version

Publisher's PDF, also known as Version of record

Link back to DTU Orbit

Citation (APA):

Zauner, D., Svalgaard, M., \& Kristensen, M. (1998). Directly UV written silica-on-silicon planar waveguides with low insertion loss. In Technical Digest Optical Fiber Communication Conference and Exhibit (pp. 149-150). IEEE. https://doi.org/10.1109/OFC.1998.657285

\section{General rights}

Copyright and moral rights for the publications made accessible in the public portal are retained by the authors and/or other copyright owners and it is a condition of accessing publications that users recognise and abide by the legal requirements associated with these rights.

- Users may download and print one copy of any publication from the public portal for the purpose of private study or research.

- You may not further distribute the material or use it for any profit-making activity or commercial gain

- You may freely distribute the URL identifying the publication in the public portal 

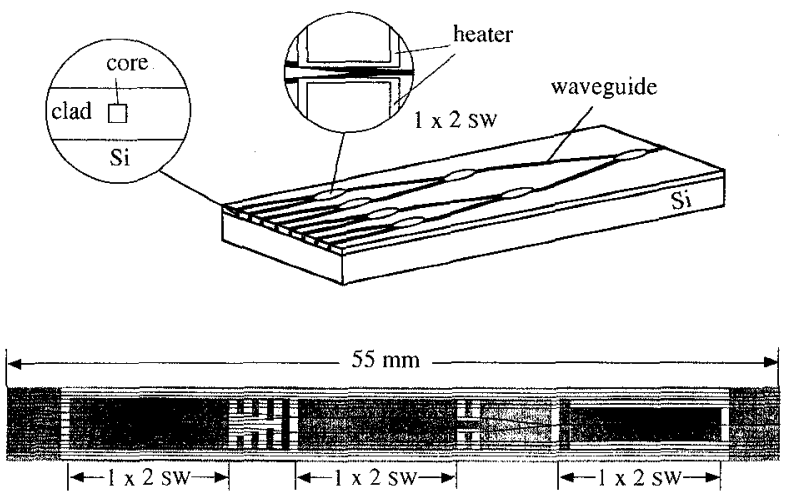

WH6 Fig. 1. Structure and photograph of the $1 \times 8$ digital optical switch using fluorinated polyimide waveguides.

talks even under rough control of driving voltage, both wavelength- and polarization-insensitive switching characteristics, high integratability, and high productivity. ${ }^{1}$ A packaged $1 \times 8$ DOS as well as a un-packaged $8 \times 8$ DOS have already been demonstrated. ${ }^{2,3}$ The key issue concerning the polymeric DOS is to establish the reliability of polymeric materials, especially under the damp heat condition for low-cost nonhermetic packages. Of these materials, a fluorinated polyimide is one of the most reliable optical polymers due to its high glass transition temperature $\left(>335^{\circ} \mathrm{C}\right)$ as well as its low water absorption $(0.2 \%)$. Loss stability of a fluorinated polyimide waveguide against high temperature $\left(300^{\circ} \mathrm{C}\right)$ and damp heat $\left(85^{\circ} \mathrm{C}, 85 \% \mathrm{RH}\right)$ has been verified. ${ }^{4}$ In this paper, we believe we demonstrate for the first time a $1 \times 8$ digital optical switch using this highly reliable fluorinated polyimide.

The fabricated $1 \times 8$ DOS has three cascading stages of $1 \times 2$ switch (SW) elements (Fig. 1). Each SW element is composed of a symmetric Y-branch with a opening angle of $0.1^{\circ}$ and two 10 -mm-long thin-film heaters $(1 \mathrm{k} \Omega$ ) for switching. The seven $1 \times 2 \mathrm{SW}$ elements are interconnected by S-bend waveguides with bending radius of $30 \mathrm{~mm}$, and the pitch of the output waveguides is $250 \mu \mathrm{m}$. As a result, the total device length is $55 \mathrm{~mm}$. The fluorinated polyimide waveguide on a Si substrate was formed by spin-coating and reactive-ion etching. The core size is $7 \times$ $7 \mu \mathrm{m}$ and the refractive index difference is $0.3 \%$. And the embedded

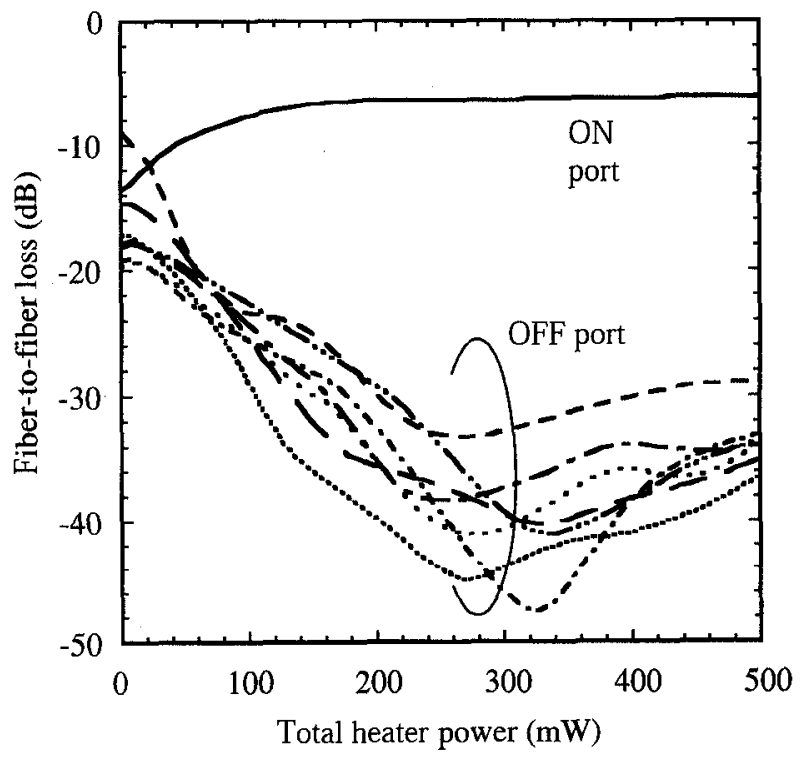

WH6 Fig. 2. Example of total heater power vs. fiber-to-fiber losses.
WH6 Table 1. Fiber-to-Fiber Insertion Losses for Eight Switched States

\begin{tabular}{|c|c|c|c|c|c|c|c|c|}
\hline ON port & port 1 & port 2 & port 3 & port 4 & port 5 & port 6 & port 7 & port 8 \\
\hline 1 & 6.4 & 27.3 & 42.2 & 41.7 & 37.7 & 33.1 & 33.3 & 30.9 \\
\hline 2 & 31.6 & 6.7 & 36.1 & 41.4 & 34.9 & 32.2 & 29.9 & 29.0 \\
\hline 3 & 30.9 & 29.0 & 6.3 & 32.1 & 32.3 & 29.8 & 28.1 & 29.1 \\
\hline 4 & 32.5 & 32.1 & 24.7 & 6.3 & 34.4 & 30.0 & 28.8 & 28.9 \\
\hline 5 & 40.1 & 37.0 & 37.9 & 39.6 & 6.3 & 25.2 & 39.5 & 34.9 \\
\hline 6 & 49.8 & 38.4 & 39.9 & 36.7 & 36.1 & 6.5 & 36.6 & 32.6 \\
\hline 7 & 50.3 & 48.7 & 42.8 & 50.9 & 37.1 & 34.0 & 6.7 & 32.2 \\
\hline 8 & 39.6 & 42.6 & 41.9 & 42.7 & 34.0 & 35.7 & 26.2 & 6.7 \\
\hline
\end{tabular}

single-mode waveguide loss was as low as $<0.4 \mathrm{~dB} / \mathrm{cm}$ at $\lambda=1.55 \mu \mathrm{m}$. A drive voltage was simultaneously applied to the three selected heaters, and power responses at $\lambda=1.55 \mu \mathrm{m}$ were measured (Fig. 2). As shown in this figure, clear digital switching behavior is observed, and the total switching power is around $300 \mathrm{~mW}(@ 10 \mathrm{~V}$ ). Table 1 lists the fiber-tofiber insertion losses for all eight switched states with a constant driving voltage of $10 \mathrm{~V}$. The average insertion loss is $6.5 \mathrm{~dB}$, and the worst-case cross talk is $18.4 \mathrm{~dB}$. The polarization-dependent losses of the $\mathrm{ON}$ ports are $<0.5 \mathrm{~dB}$. The insertion loss consists of a propagation loss of $2.2 \mathrm{~dB}$, coupling losses of $0.2 \mathrm{~dB}$, and excess losses of $S W$ elements of $3 \times 1.4 \mathrm{~dB}$. The excess loss is mainly caused by the optical scattering due to voids between the Y-branch arms in the burying cladding layer. Thus, the insertion loss is expected to be reduced to $\angle 4 \mathrm{~dB}$ by optimizing the fabrication process.

In summary, we have successfully demonstrated a polymeric $1 \times 8$ digital optical switch using a highly reliable fluorinated polyimide. The fabricated switch has an average insertion loss of $6.5 \mathrm{~dB}$ and cross talks of $<-18 \mathrm{~dB}$ at $\lambda=1.55 \mu \mathrm{m}$. These results show an excellent potential for the practical use of this switch in optical networks.

1. M.K. Keorkamp et al., in Integrated Photonics Research, Vol. 3 of 1994 OSA Technical Digest Series (Optical Society of America, Washington, D.C., 1994), pp. 274-276.

2. W. Horsthuis et al., in Proceedings of 21st European Conference on Optical Communication (ECOC'95), 1995, pp. 1059-1062.

3. A. Borreman et al., in Proceedings of 22nd European Conference on Optical Communication (ECOC'96), 1996, pp. 59-62.

4. T. Matsuura et al., Electron. Lett. 29, 2107-2109 (1993).

WH7

3:00pm

Directly UV written silica-on-silicon planar waveguides with low insertion loss

\section{Zauner, M. Svalgaard, M. Kristensen, Mikroelektronik Centret (MIC), Bldg. 345 east, Technical University of Denmark, DK-2800, Lyngby, Denmark; E-mail: dz@mic.dtu.dk}

The fabrication techniques currently used for production of silica-based planar waveguides often rely on photolithography and reactive ion etching. However, the photosensitive properties of germanosilica may be utilized to directly induce waveguide patterns into thin-film structures using ultraviolet (UV) light. ${ }^{1}$ The advantages of fabricating planar waveguides with UV light include the absence of photolithography and 
reactive ion etching, flexibility in waveguide geometry, and excellent control of the refractive index step. Direct UV writing of waveguides became a realistic alternative to other fabrication methods when propagation losses below $0.2 \mathrm{~dB} / \mathrm{cm}$ were reported in single-mode waveguides. ${ }^{2}$ However, the coupling loss to optical fibers remained high, typically $1.8 \mathrm{~dB} /$ facet, which is significantly more than that obtained with other techniques.

In this paper we present results in which the coupling loss to optical fibers has been lowered substantially. In addition, the glass photosensitivity has been increased, thus permitting shorter fabrication times.

The sample used for UV writing was deposited on a 4 in. silicon wafer using plasma-enhanced chemical vapor deposition. First a $12-\mu \mathrm{m}$ $\mathrm{SiO}_{2}$ buffer layer was deposited followed by a $7-\mu \mathrm{m} \mathrm{GeO}_{2}-\mathrm{B}_{2} \mathrm{O}_{3}-\mathrm{SiO}_{2}$
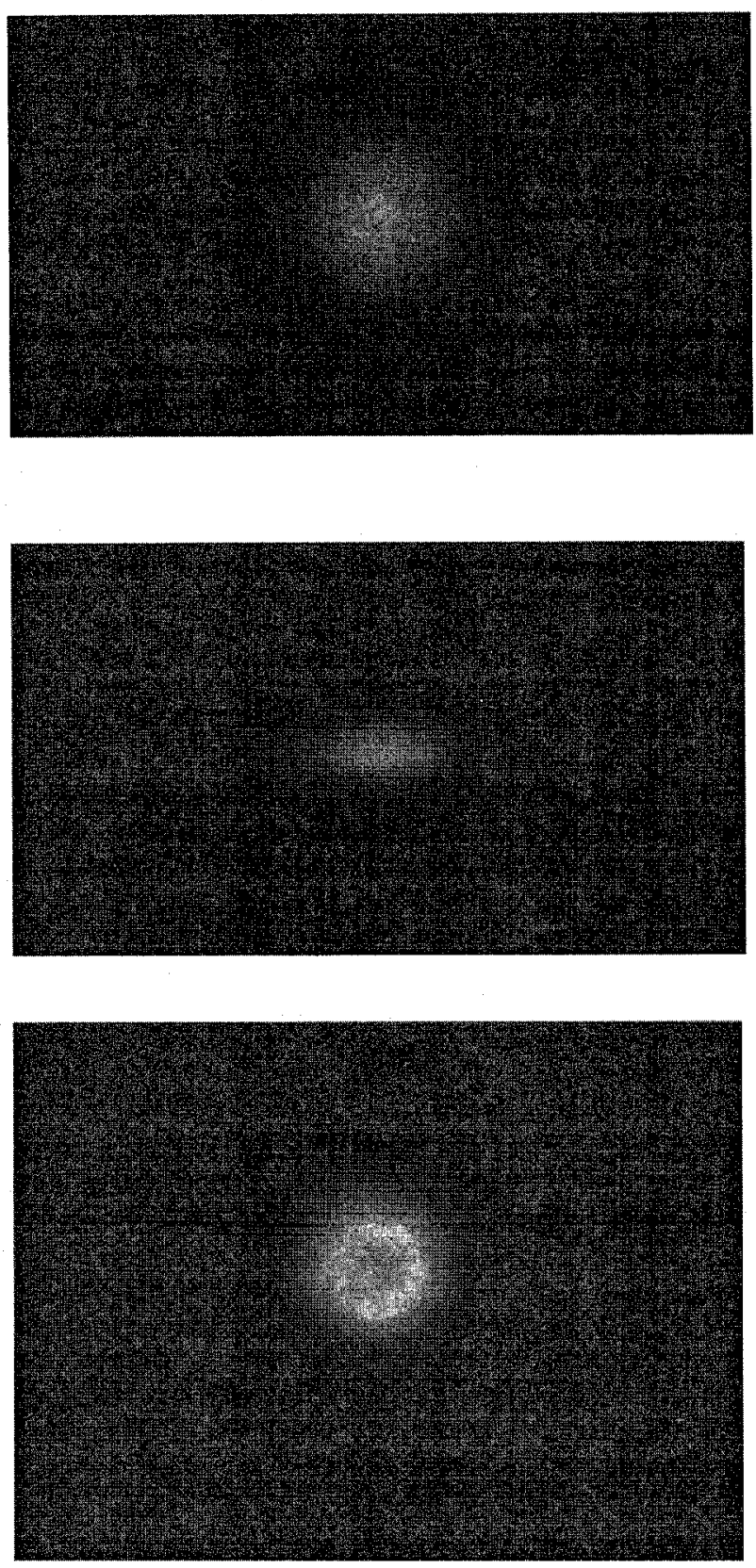

WH7 Fig. 1. CCD camera recordings of the mode intensity profiles. Top: fiber, middle: sample from Ref. 2 and bottom: Boron-doped sample. The elliptical shape (middle) giving rise to high coupling loss is changed to a nearly circular shape (bottom) by the index matching of core and buffer/cladding. photosensitive core layer and finally a $12-\mu \mathrm{m} \mathrm{P}_{2} \mathrm{O}_{5}-\mathrm{B}_{2} \mathrm{O}_{3}-\mathrm{SiO}_{2}$ cladding. The refractive indices of this buffer-core-cladding structure were $n_{1}-n_{2}$ $-\mathrm{n}_{3}=1.4570-1.4588-1.4573$, measured at $633 \mathrm{~nm}$. The sample was loaded prior to UV exposure with $\sim 2$ mole\% deuterium to increase the photosensitivity. Linear waveguides were written by scanning the sample under a $90 \mathrm{~mW}$, cw 244-nm laser beam ${ }^{2}$ focussed to a spotsize of $\sim 7 \mu \mathrm{m}$. The sample was annealed after the UV exposure at $80^{\circ} \mathrm{C}$ to remove residual deuterium. Insertion loss measurements were performed by coupling light from a $1.54-\mu \mathrm{m}$ laser diode to the waveguides using standard single-mode fibers and index-matching oil. The near field of the guided mode was imaged on a CCD camera by replacing the output fiber with a $\times 40$ microscope objective.

Samples used previously did not contain $\mathrm{B}_{2} \mathrm{O}_{3}$ in the core layer resulting in large index steps between the core and buffer/cladding layers. ${ }^{2}$ In these nonindex-matched samples the high index of the core layer causes the mode profile of a UV written waveguide to be elliptical (Fig. 1, middle). The guided-mode intensity distribution is typically $4 \times 10 \mu \mathrm{m}$ FWHM and the total insertion loss is $4 \mathrm{~dB}$ for a 3 -cm-long waveguide written with a scan speed of $300 \mu \mathrm{m} / \mathrm{s}$. When matching the core layer index to that of the buffer/cladding layers the mode profile of a waveguide written with a scan speed of $1000 \mu \mathrm{m} / \mathrm{s}$ (Fig. 1, bottom) closely resembles that of a fiber (Fig. 1, top). The corresponding insertion loss is $0.6 \mathrm{~dB}$ ( 30 -mm-long waveguide), clearly demonstrating that both low coupling- and propagation loss has been achieved. In addition, the presence of $\mathrm{B}_{2} \mathrm{O}_{3}$ significantly increases the photosensitivity, so that sufficient index changes may be obtained with scan speeds that are three times higher than before. These results show that direct UV writing now constitutes a cheap, fast and flexible fabrication technique for low-loss, singlemode waveguides.

1. M. Svalgaard, C.V. Poulsen, A. Bjarklev, O. Poulsen, Electron. Lett. 30, 1401-1402 (1994).

2. M. Svalgaard and M. Kristensen, Electron. Lett. 33, 861-862 (1997).

3:15pm

\section{Polymeric $4 \times 4$ digital optical switch matrix based on oversized rib waveguides}

\section{R. Moosburger, B. Schüppert, G. Fischbeck, C. Kostrzewa, K. Petermann, Technische Universität Berlin, Fachbereich 12, Fachgebiet Hochfrequenztechnik, Einsteinufer 25, 10587 Berlin, Germany; E-mail: moosbur@sun6hft.ee.tu-berlin.de}

Integrated photonics research is currently facing a demand for increasingly complex devices to satisfy the requirements for the evolving optical communication networks. Up to $8 \times 8$ switch matrices have been fabricated in various material systems, which are all based on low index contrast waveguides. ${ }^{1-3}$ We have previously published a novel polymeric thermo-optic $1 \times 2$ digital optical switch (DOS) that utilizes an oversized rib waveguide structure to allow for the use of many standard polymers with arbitrary high index contrasts. ${ }^{4}$ In this paper we investigate the feasibility of this concept for large scale integration by the realization of a thermo-optic $4 \times 4$ DOS-matrix composed of $241 \times 2$-switch elements.

The layout of the fabricated device is shown in Fig. 1. To achieve a strictly nonblocking and robust space matrix, a series of $1 \times 2$ DOS elements are arranged in a tree structure. The elements are connected with $S$-bends having a radius of $15 \mathrm{~mm}$ and minimum intersection angles of $22^{\circ}$. Single-mode waveguides with a core height of $5.5 \mu \mathrm{m}$ were 